\title{
Microsatellite markers developed for a Swedish population of sand lizard (Lacerta agilis)
}

Tonia S. Schwartz · Mats Olsson

Published online: 12 March 2008

(C) Springer Science+Business Media B.V. 2008

Erratum to: Conserv Genet

DOI 10.1007/s10592-006-9238-2

The original article contained the incorrect version of Table 1. This is the correct version:

The online version of the original article can be found under doi:10.1007/s10592-006-9238-2.

T. S. Schwartz $(\bowtie) \cdot M$. Olsson Institute for Conservation Biology, School of Biological Sciences, University of Wollongong, Northfields Ave,

Wollongong 2522, NSW, Australia

e-mail: schwartz@iastate.edu

Present Address:

T. S. Schwartz

2102 Molecular Biology, Iowa State University,

Ames, IA 50011, USA 


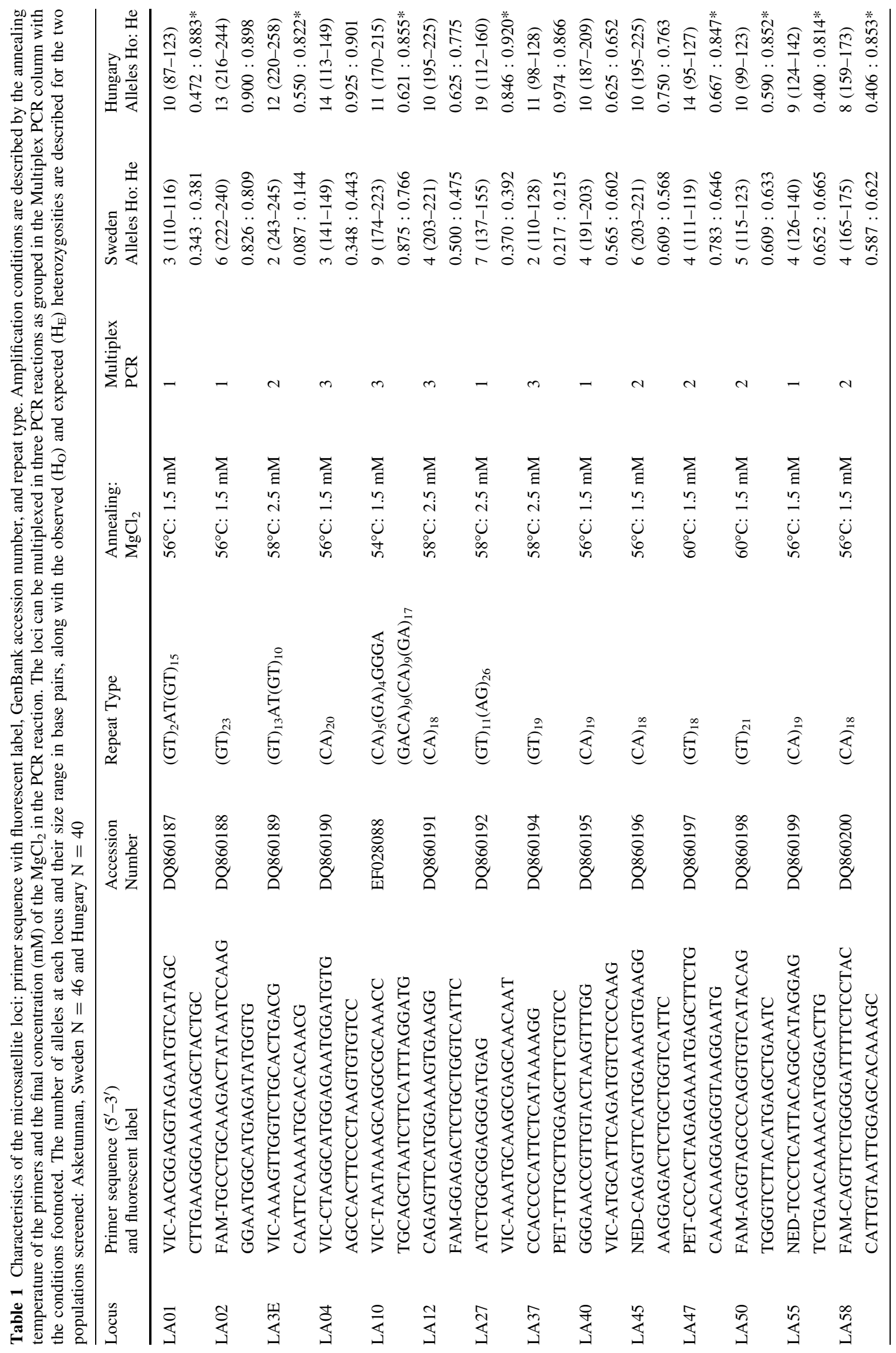




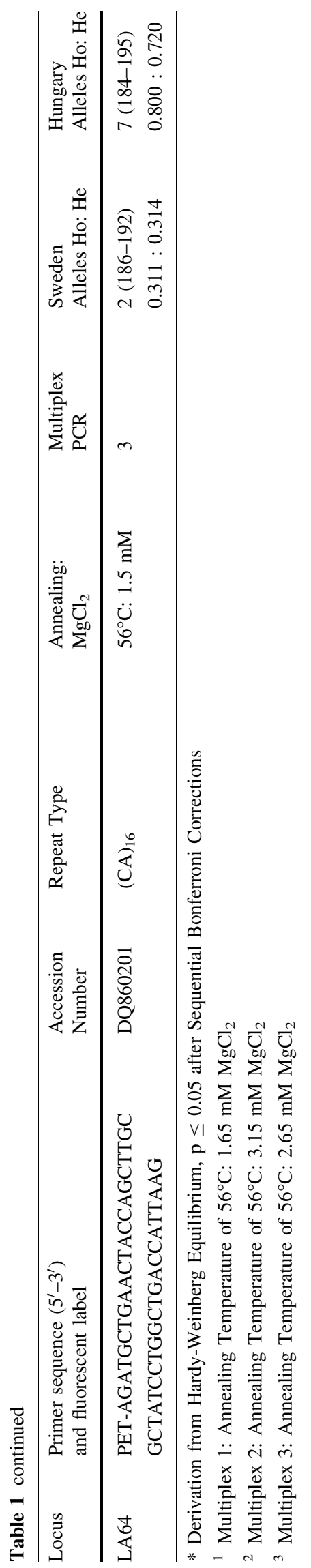

